\title{
Study on association between genetic polymorphisms of haem oxygenase-1, tumour necrosis factor, cadmium exposure and malaria pathogenicity and severity
}

\author{
Jiraporn Kuesap ${ }^{1}$, Kenji Hirayama², Mihoko Kikuchi², Ronnatrai Ruangweerayut ${ }^{3}$, Kesara Na-Bangchang ${ }^{1 *}$
}

\begin{abstract}
Background: Malaria is the most important public health problems in tropical and sub-tropical countries. Haem oxygenase $(\mathrm{HO})$ enzyme and the pro-inflammatory cytokine tumour necrosis factor (TNF) have been proposed as one of the factors that may play significant role in pathogenicity/severity of malaria infection. $\mathrm{HO}$ is the enzyme of the microsomal haem degradation pathway that yields biliverdin, carbon monoxide, and iron. In this study, the association between malaria disease pathogenicity/severity and $(\mathrm{GT})_{\mathrm{n}}$ repeat polymorphism in the promoter region of the inducible HO-1 including the effect of cadmium exposure (potent inducer of HO-1 transcription) as well as polymorphism of TNF were investigated.
\end{abstract}

Methods: Blood samples were collected from 329 cases non-severe malaria with acute uncomplicated Plasmodium falciparum malaria (UM) and 80 cases with Plasmodium vivax malaria (VM), and 77 cases with severe or cerebral malaria (SM) for analysis of genetic polymorphisms of HO-1 and TNF and cadmium levels. These patients consisted of 123 (25.3\%) Thai, 243 (50.0\%) Burmese and 120 (24.7\%) Karen who were present at Mae Sot General Hospital, Mae Sot, Tak Province, Thailand.

Results: The number of $(\mathrm{GT})_{\mathrm{n}}$ repeats of the HO-1 gene in all patients varied between 16 and 39 and categorized to short (S), medium (M) and long (L) GT repeats. The genotype of $(G T)_{n}$ repeat of HO-1 was found to be significantly different among the three ethnic groups of patients. Significantly higher frequency of $S / L$ genotype was found in Burmese compared with Thai patients, while significantly lower frequencies of $S / S$ and $M / L$ but higher frequency of M/M genotype was observed in Burmese compared with Karen patients. No significant association between HO-1 and TNF polymorphisms including the inducing effect of cadmium and malaria pathogenicity/severity was observed.

Conclusions: Difference in the expression of HO-1 genotype in different ethnic groups may contribute to different severity of malaria disease. With this limited sample size, the finding of the lack of association between malaria disease pathogenicity/severity genetic polymorphisms of HO-1 (GT) n repeat as well as TNF observed in this study may not entirely exclude their possible link with malaria disease pathogenicity/severity. Further study in larger sample size is required.

\footnotetext{
* Correspondence: kesaratmu@yahoo.com

'Pharmacology and Toxicology Unit, Graduate Programme in Biomedical

Sciences, Thammasat University, Pathumthani, Thailand

Full list of author information is available at the end of the article
} 


\section{Background}

Malaria remains an important health problem in several countries in the world especially in Thailand $[1,2]$. Cerebral malaria is one of the major pathological complications of Plasmodium falciparum infection in humans, manifesting as coma that can lead to death. The pathogenesis of cerebral malaria remains controversial, but major factors involved, i.e., cytokines and adhesion molecules are well documented [3]. In Thailand, malaria is still problematic in particular areas, especially in the forest and forest fringes along international borders where there is significant population movement. The highest cases of malaria in 2009 were reported from Tak Province, where Mae Sot District is located. They have carried the largest burden of malaria diagnosis and treatment for foreigners, the majority of whom are from Myanmar [2]. Mae Sot District is also an endemic area polluted with high levels of cadmium [4-6]. The degree of soil cadmium contamination is associated with rice grain cadmium contamination downstream of an actively mined zone of zinc mineralization in Mae Sot District [6]. Population cadmium exposure is due mainly to eating contaminated food, smoking cigarettes, and occupation in cadmium-contaminated places [7]. There have been several reports on the involvement of cadmium in nephropathy $[5,7,8]$.

Haem oxygenase (HO) enzyme is proposed as one of the factors that may play role in pathogenesis including susceptibility and severity of malaria disease $[9,10]$. The isoforms HO-1 and HO-2, are microsomal enzymes that play important role in haem catabolism to produce biliverdin/bilirubin, carbonmonoxide and iron [9,11-13]. The promoter region of $\mathrm{HO}-1$ gene contains cadmium response element (CdRE), the binding site for cadmium which is a potent inducer of HO-1 transcription [14]. Therefore, it may be possible that the linkage of cadmium exposure and susceptibility to malaria disease is through binding of cadmium to CdRE of the HO- 1 gene. The polymorphism of human HO-1 gene promoter compose of the single nucleotide polymorphism $(\mathrm{SNPs})$ and $(\mathrm{GT})_{\mathrm{n}}$ dinucleotide polymorphism which may contribute to the fine tuning of the transcription. Long $(\mathrm{GT})_{\mathrm{n}}$ alleles have been found associated with susceptibility to smoking-induced emphysema or coronary artery disease, while they may be linked to resistance to cerebral malaria $[10,15,16]$.

TNF is a cytokine produced primarily by monocytes and macrophages in many inflammatory diseases. SNPs of the TNF promoter have been reported to be associated with susceptibility to severe malaria. Four mutations are transitions of adenosine to guanine and are located at nucleotide positions -238, -244, -308, and -376 , relative to the transcriptional site $[17,18]$. Various studies have investigated the relation existing between TNF promoter alleles and severity of malaria. TNF has been shown to be elevated in severe malaria [19], and TNF promoter region -238A allele together with $-376 \mathrm{~A}$ allele are associated with susceptibility to severe malaria $[20,21]$. Furthermore, TNF P-D allele has been shown significantly associated with cerebral malaria in our previous study in Karen and Burmese populations [22].

In this study, the $(G T)_{n}$ repeat polymorphism in the promoter region of the inducible $\mathrm{HO}-1$ and six mutations of TNF from malaria patients (Thai, Burmese and Karen), in Mae Sot endemic area, were analysed. The aim was to determine the association between genetic polymorphisms of HO-1, TNF and severity of malaria infection.

\section{Methods}

\section{Subjects and blood collection}

A total of 486 malaria patients infected with $P$. falciparum and $P$. vivax (aged between three and 73 years, parasitaemia ranged from 77 and $1,840,000 / \mu \mathrm{l}$ ) comprising 123 (25.3\%) Thai, 243 (50.0\%) Burmese and $120(24.7 \%)$ Karen who were present at Mae Sot General Hospital, Mae Sot, Tak Province, Thailand, were recruited into the study. The study protocol was approved by the Ethics Committee of the Ministry of Public Health, Thailand. All patients gave informed consents for study participation prior to the study enrolment.

Blood samples were collected from 329 cases nonsevere malaria with acute uncomplicated $P$. falciparum malaria (UM) and 80 cases with $P$. vivax malaria (VM), and 77 cases with severe or cerebral malaria (SM) for analysis of genetic polymorphisms of $\mathrm{HO}-1$ and TNF and cadmium levels.

\section{Extraction of genomic DNA}

Genomic DNA was extracted from packed white blood cells (buffy coat layers) using standard phenol-chloroform extraction technique [23].

\section{Microsatellite polymorphism}

To amplify the (GT) $)_{\mathrm{n}}$ microsatellite located at position -270 of $\mathrm{HO}-1$ gene promoter, the PCR assays were performed over 35 cycles of $30 \mathrm{~s}$ at $95^{\circ} \mathrm{C}, 30 \mathrm{~s}$ at $60^{\circ} \mathrm{C}$, and $3 \mathrm{~min}$ at $72^{\circ} \mathrm{C}$. A fluorescently labelled primer $\mathrm{p} 1$ (5'-AGAGCCTGCAGCTTCTCAGA-3') and an unlabeled antisense primer $\mathrm{p} 2$ (5'-ACAAAGTCTGGCCATAGGAC-3') was designed according to the published sequence [24]. The PCR products were analysed by a laser-based automated DNA sequencer, ABI 3730 DNA Analyzer (Applied Biosystems, Foster City, Calif., USA). 


\section{Direct sequencing}

To analysis of six-biallelic polymorphic sites (TNF1,031T/C, -863C/A,-857C/T, -376G/A, -308G/A, and $-238 \mathrm{G} / \mathrm{A}$ ) in the 5 -flanking region of TNF gene, a 1,042-bp DNA fragment spanning the 5 -flanking region of the TNF gene from position -66 to $-1,107$ were amplified by PCR. The primers for the PCR reactions and the method for direct sequencing followed the methods described by Higuchi [25] and Ubalee [22].

\section{Analysis of cadmium levels}

Cadmium levels in plasma samples collected from 138 patients with malaria (13 cases with SM, 92 cases with UM and 33 cases with VM) were measured by Graphite Furnace Atomic Absorption Spectrophotometer (GFAAS) [26]. Analysis of cadmium in blood was not possible due to limited blood sample volume. The threshold level of blood cadmium defined by the World Health Organization is $0.5 \mu \mathrm{g} / \mathrm{L}$ [27].

\section{Statistical analysis}

Statistical analysis was performed using SPSS version 12.0 software (SPSS Co., Ltd., Thailand). Statistical significance level for all tests was set at $\alpha=0.05$. The frequencies of HO-1 and TNF genotype alleles were summarized as number of cases and percentage values. The association between genetic polymorphisms of HO1 including TNF and ethnicity and malaria disease pathogenicity/severity (UM, SM, VM) were determined using Chi-square test. The concentrations of cadmium in plasma were presented as median (range) values for data not conforming to normal distribution. The association between the level of cadmium exposure and malaria disease pathogenicity/susceptibility/severity was performed by Kruskal Wallis tests. Difference in proportions among ethic groups and disease pathogenicity/susceptibility/severity was determined by Chi-square test.

\section{Results}

The polymorphism of (GT) $)_{n}$ repeat of human HO-1 and association with malaria disease pathogenicity/ susceptibility/severity

The number of $(\mathrm{GT})_{\mathrm{n}}$ repeats of the HO-1 gene varied between 16 and 39 in all patients (Figure 1). It was categorized to short (16-27), medium (28-33) and long (3439) of $\mathrm{GT}_{n}$ repeats. The allele frequencies of $(\mathrm{GT})_{\mathrm{n}}$ allele were similar in the three ethnic groups. With regards to the frequencies of the genotypes $(\mathrm{S} / \mathrm{S}, \mathrm{S} / \mathrm{M}, \mathrm{S} / \mathrm{L}, \mathrm{M} / \mathrm{M}$, $\mathrm{M} / \mathrm{L}, \mathrm{L} / \mathrm{L}$ ) of $(\mathrm{GT})_{\mathrm{n}}$ repeats (Table 1 ), significantly higher frequency of S/L genotype was found in Burmese compared with Thai patients. However, significantly lower frequencies of $S / S$ and $M / L$ but higher frequency of $\mathrm{M} / \mathrm{M}$ genotype was found in Burmese compared with Karen patients. When data were combined for all ethnic groups, no association between malaria disease severity and $\mathrm{HO}-1$ genotype was observed.

\section{The polymorphism of TNF alleles and association with malaria pathogenicity/susceptibility/severity}

The patterns of SNPs in TNF alleles in the three ethnic groups were observed based on five [22] and three [28] point mutations as shown in Tables 2 and 3. For the five SNPs of biallelic polymorphism sites $(-1031,-863$, $-857,-308,-238$ ), six types of TNF promoter (TNF P) allele polymorphism were found, i.e., TNF P-A, TNF PB, TNF P-C, TNF P-D, TNF P-E and TNF P-F. For the pattern of three SNPs of biallelic polymorphism sites $(-1031,-863,-857)$, five types of TNF P allele polymorphism were observed, i.e., TNF P-1, TNF P-2, TNF P-3, TNF P-4 and TNF P-5. There was no significant difference in the frequencies of each mutation among all the three ethnic groups. In addition, when data were combined for all ethnic groups, lack of association between any pattern of TNF allele polymorphism as well as each individual single SNP and malaria disease pathogenicity/severity was found.

\section{Cadmium levels and association with malaria pathogenicity/susceptibility/severity}

When data were combined for the three ethnic groups, a trend of higher plasma cadmium levels in falciparum infection [median (range) values of $0.16(0.03-2.34)$ and $0.24(0.01-3.18) \mu \mathrm{g} / \mathrm{L}$ for $\mathrm{SM}$ and $\mathrm{UM}$, respectively] compared with VM $[0.10(0.01-0.33) \mu \mathrm{g} / \mathrm{L}]$, was observed. In the group with cadmium levels $<0.5 \mathrm{mg} / \mathrm{L}$, the proportions of patients with SM $(\mathrm{n}=10,76.9 \%)$ and $\mathrm{UM}(\mathrm{n}=74,80.4 \%)$ were significantly lower than VM $(\mathrm{n}=33,100 \%)$, and in addition, the proportion of Thai patients $(\mathrm{n}=18,66.7 \%)$ was significantly lower than Burmese ( $\mathrm{n}=81,91.0 \%)$.

\section{Discussion}

The association between human haem oxygenase-1 (HO-1) and pathogenicity/severity of malaria infection was described in a few studies in vitro including molecular epidemiological investigation from brain lesion $[24,29,30]$ and the hypothetical roles of $\mathrm{HO}-1$ in pathogenesis of cerebral malaria was proposed by Shibahara [10]. However, only one research article which provides evidence on the association between $(\mathrm{GT})_{\mathrm{n}}$ repeat polymorphism of HO-1 and malaria pathogenicity/severity was reported in Karen ethnic minority group with cerebral malaria and acute uncomplicated falciparum malaria who resided in areas along the Thai-Myanmar border [24]. In that study, the proportion of patients with short $(\mathrm{GT})_{\mathrm{n}}$ alleles was found to be significantly higher in cerebral malaria (SM) than UM. Short $(G T)_{n}$ alleles in the promoter region may therefore represent a 


\section{a. Thai patients}

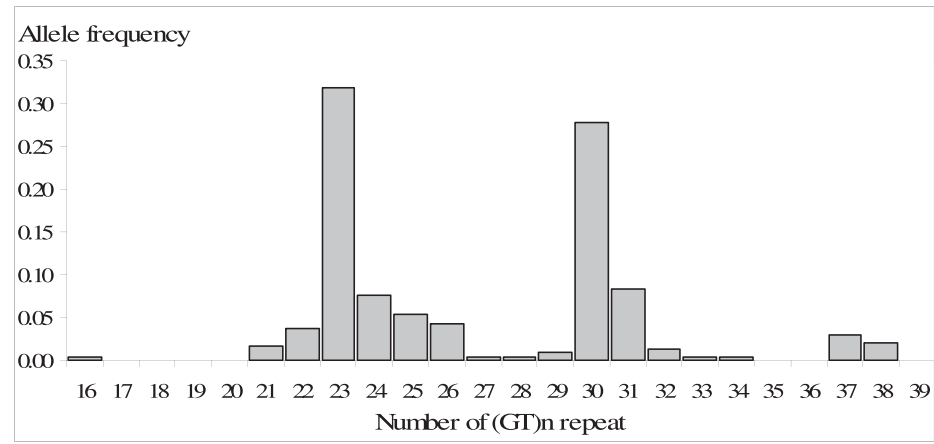

b. Burmese patients

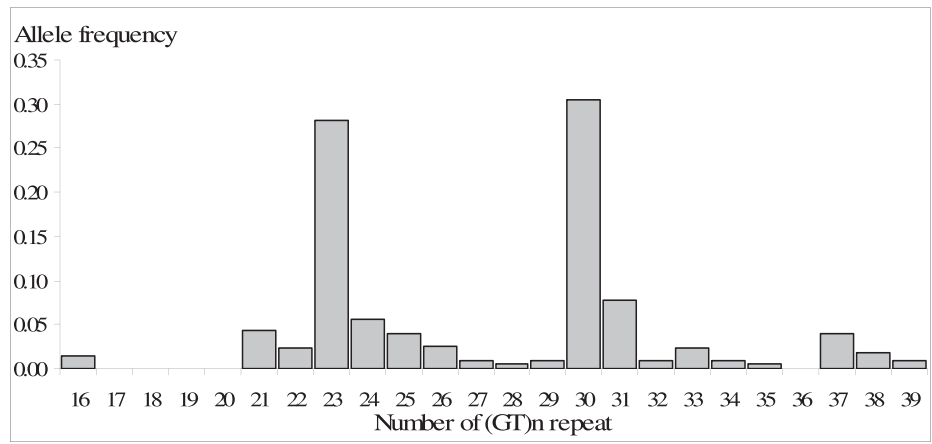

c. Karen patients

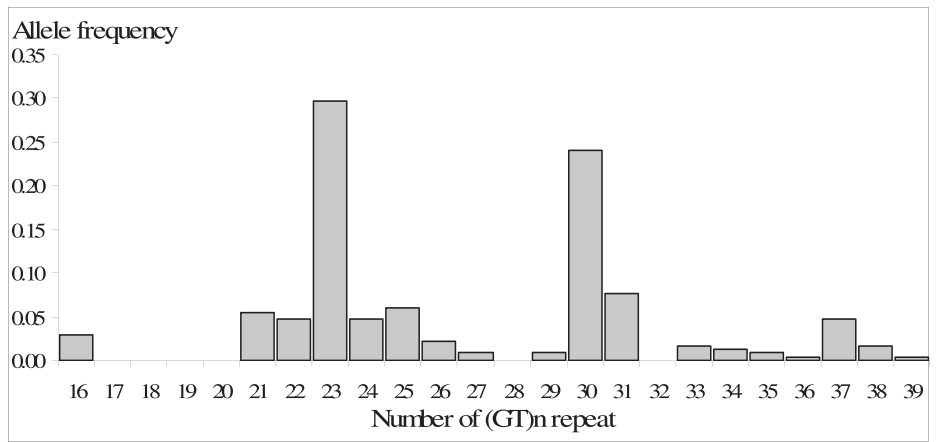

Figure 1 Frequency distribution of $(G T)_{n}$ repeats in three ethnic groups of patients

genetic risk factor for cerebral malaria as in may directly enhance the transcription of $\mathrm{HO}-1$ in malaria patients, and as a consequence, the products of haem degradation, i.e., CO, iron and bilirubin, may increase in the brain lesion. Furthermore, the influence of the $(G T)_{n}$ repeat polymorphisms in the HO-1 gene promoter was investigated in different cell lines where constructs with lengths of less than 25 repeats (short repeat) showed an increasing HO-1 basal promoter activity [31] or transcriptional up-regulation in response to various stimuli as compared to that with greater than 25 repeats [15]. Increasing transcriptional up-regulation leads to high activity of HO-1 enzyme and thus, the haem degradation products particularly iron, which is an essential supply for growth and proliferation of malaria parasite. Excess amount of iron might trigger high parasitaemia causing red blood cell haemolysis and severe malaria including cerebral malaria.

The present study, due to limitation of available data on $(\mathrm{GT})_{\mathrm{n}}$ repeat polymorphism of HO-1 in different patient populations with different malaria severity, estimation of proper sample size was not possible. There appears to be a significant difference in HO-1 genotypes among the three ethnics. This may explain difference in pathogenicity/severity of malaria infection in various ethnics. The frequencies of short $(\mathrm{GT})_{\mathrm{n}}$ alleles 
Table 1 Distribution of HO-1 promoter genotypes and allele frequencies of the three ethnics (Thai, Burmese, Karen) of malaria patients

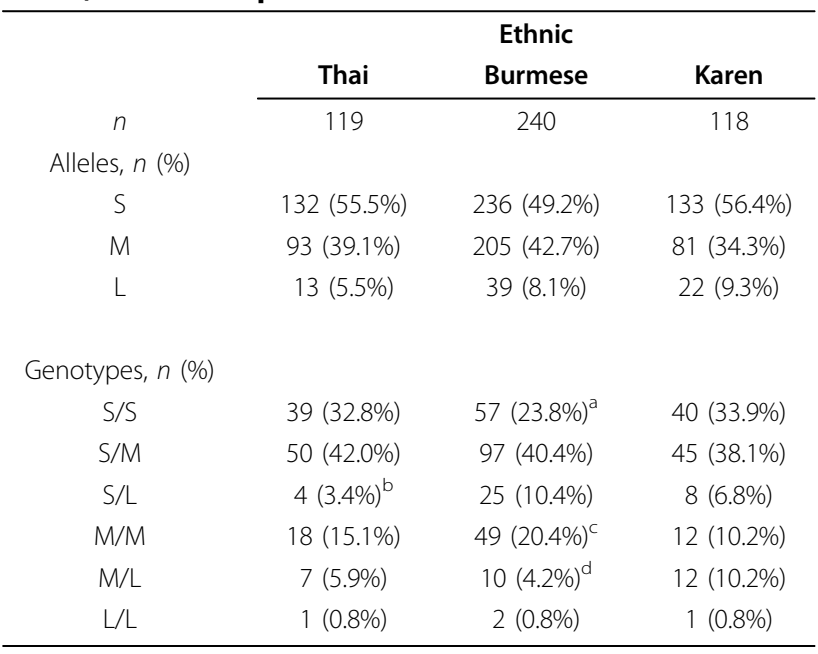

${ }^{\mathrm{a}} p=0.042,95 \% \mathrm{Cl}$ of odd ratio: $0.37-0.98$ for Burmese vs Karen (Chi-square test)

${ }^{\mathrm{b}} p=0.021,95 \% \mathrm{Cl}$ of odd ratio: $0.10-0.88$ for Thai vs Burmese (Chi-square test)

${ }^{c} p=0.015,95 \% \mathrm{Cl}$ of odd ratio: $1.15-4.45$ for Burmese vs Karen (Chi-square test)

${ }^{d} p=0.026,95 \% \mathrm{Cl}$ of odd ratio: $0.16-0.92$ for Burmese vs Karen (Chi-square test)

(S/S) genotype in the three groups of patients with different disease severity (combined ethnics) were found to be comparable. This lack of association could represent a genuine finding, or else, a low study power due to inadequate sample size (particularly in the SM group). In addition, the major confounding factor ethnics cannot be excluded. In a previous study, a significant association between the short $(\mathrm{GT})_{\mathrm{n}}$ alleles $(\mathrm{S} / \mathrm{S})$ polymorphism of HO-1 gene promoter and increased risk of cerebral malaria (severe malaria) has been demonstrated in 150 Burmese and Karen patients [24]. Nevertheless, the sample size included in that study was unbalanced and also too small (30 cases of cerebral malaria, 120 cases of UM) to provide a definitive conclusion on such association. The finding of the lack of association between genetic polymorphism of $\mathrm{HO}-1$ $(\mathrm{GT})_{\mathrm{n}}$ repeat and malaria disease pathogenicity/severity found in this study may not entirely exclude the possible link between HO-1 enzyme activity and malaria disease pathogenicity/severity. Results from recent in vitro study provide insight into the molecular mechanism of induction of HO-1 activity and the link with malaria pathogenicity/severity $[10,24]$. Treatment of astrocyte (CCF-STTG1) and retinal pigment epithelial (ARPE-19, D407) cells with exogenous prostaglandin $\mathrm{D}_{2}\left(\mathrm{PGD}_{2}\right)$ and $15 \mathrm{~d}-\mathrm{PGJ}_{2}$ (metabolite of $\mathrm{PGD}_{2}$ ) consistently induced the expression of HO-1 mRNA and protein $[32,33]$. $\mathrm{PGD}_{2}$ is a major prostanoid produced in the brain and is involved in the regulation of sleep and pain responses [34].

Cadmium has been shown to be a potent inducer of HO- 1 activity $[14,35]$, and as a consequence, this might be linked to severity of malaria disease. Blood cadmium reflects recent cadmium exposure, whereas urinary cadmium indicates body accumulation of cadmium $[7,36]$. The ratio of plasma to blood cadmium varies from 3 to $16 \%$ [37]. The observed median (range) values of plasma cadmium concentrations in the VM, UM and SM groups of patients were 0.10 (0.01-0.33), 0.24 (0.01-3.18) and $0.16(0.03-2.34) \mu \mathrm{g} / \mathrm{L}$, respectively. Twenty-one patients (in SM and UM groups) had the concentrations above the tolerance limit of $0.5 \mu \mathrm{g} / \mathrm{L}$ [38]. The information on blood cadmium concentrations in Thai population has been reported in non-occupational females living in Bangkok and other areas, with the geometric mean blood levels of 0.40 and $0.43 \mu \mathrm{g} / \mathrm{L}$, respectively [39]. The observed concentrations of cadmium in plasma in malaria patients were considered higher than non-occupational residents in other areas due to the fact that cadmium level in plasma is only about $3-16 \%$ of that in blood [40]. Although the concentrations of plasma cadmium are still considered low considering the threshold level of $0.5 \mathrm{mg} / \mathrm{L}$, results may more or less explain the high incidence of malaria case report, mortality and morbidity from this high cadmium pollutant area of Mae Sot. It appears that plasma cadmium

Table 2 Six TNF alleles polymorphism (TNF P-A, TNF P-B, TNF P-C, TNF P-D, TNF P-E, TNF P-F) based on five SNPs of biallelic polymorphism sites $(-238,-308,-857,-863,-1031)$ in patients with severe (SM), uncomplicated falciparum (UM) and vivax malaria (VM) cases when data were combined for the three ethnic groups

\begin{tabular}{|c|c|c|c|c|c|c|c|c|}
\hline \multirow[t]{2}{*}{ TNF type } & \multicolumn{5}{|c|}{ Polymorphic sites of the promoter region of TNF- $\alpha$ gene } & \multirow{2}{*}{$\begin{array}{l}\text { SM } \\
\text { (\%) }\end{array}$} & \multirow{2}{*}{$\begin{array}{l}\text { UM } \\
\text { (\%) }\end{array}$} & \multirow{2}{*}{$\begin{array}{l}\text { VM } \\
\text { (\%) }\end{array}$} \\
\hline & -238 & -308 & -857 & -863 & -1031 & & & \\
\hline TNFP-A & G & G & C & C & $\mathrm{T}$ & 41.3 & 52.3 & 53.5 \\
\hline TNFP-B & G & G & C & A & C & 39.7 & 33.8 & 33.8 \\
\hline TNFP-C & A & G & C & C & C & 3.2 & 3.3 & 4.2 \\
\hline TNFP-D & G & G & $\mathrm{T}$ & C & $\mathrm{T}$ & 6.3 & 4.3 & 3.5 \\
\hline TNFP-E & G & A & C & C & $\mathrm{T}$ & 7.9 & 5.0 & 3.5 \\
\hline TNFP-F & G & G & C & A & $\mathrm{T}$ & 1.6 & 1.3 & 1.4 \\
\hline
\end{tabular}


Table 3 Five TNF alleles polymorphism (TNF P-1, TNF P-2, TNF P-3, TNF P-4, TNF P-5) based on three SNPs of biallelic polymorphism sites $(-857,-863,-1031)$ in patients with severe (SM), uncomplicated falciparum (UM) and vivax malaria (VM) cases when data were combined for the three ethnic groups

\begin{tabular}{|c|c|c|c|c|c|c|}
\hline \multirow[t]{2}{*}{ TNF type } & \multicolumn{3}{|c|}{ Polymorphic sites of the promoter region of TNF- $\alpha$ gene } & \multirow{2}{*}{$\begin{array}{l}\text { SM } \\
\text { (\%) }\end{array}$} & \multirow{2}{*}{$\begin{array}{l}\text { UM } \\
\text { (\%) }\end{array}$} & \multirow{2}{*}{$\begin{array}{l}\text { VM } \\
\text { (\%) }\end{array}$} \\
\hline & -857 & -863 & -1031 & & & \\
\hline TNFP-1 & C & C & $T$ & 49.2 & 57.2 & 57.7 \\
\hline TNFP-2 & $\mathrm{T}$ & C & $\mathrm{T}$ & 6.3 & 4.3 & 3.5 \\
\hline TNFP-3 & C & A & C & 39.7 & 34.5 & 34.5 \\
\hline TNFP-4 & C & C & C & 3.2 & 3.0 & 3.5 \\
\hline TNFP-5 & C & A & $\mathrm{T}$ & 1.6 & 1.0 & 0.7 \\
\hline
\end{tabular}

concentrations tended to be higher in patients with falciparum malaria (UM and SM) compared with VM. In addition, significantly lower proportions of cases with falciparum malaria including both UM (80.4\%) and SM (76.9\%) were found compared with VM (100\%) at plasma cadmium level of $\leq 0.5 \mu \mathrm{g} / \mathrm{L}$. Cadmium is known to produce toxic effect to human and other organisms including malaria parasite when exposing with high level of cadmium. It is possible that optimally high levels of cadmium might promote the growth of $P$. falciparum but not with $P$. vivax by inducing HO-1 activity to produce iron. The mechanism(s) by which parasite transport or demolish cadmium are, therefore, important for their survival. It has been reported that P. falciparum efflux cadmium from cells through PFMDR2 protein [41]. Again, due to limited sample size and confounding factors (age, gender, ethnic), definitive conclusion on this association could not be obtained. Cadmium concentrations have been reported to vary markedly according to age, gender and ethnic $[42,43]$ and results from the present study also revealed some association between ethnicity (Thai vs Burmese) and cadmium levels in group with level of $\leq 0.5 \mu \mathrm{g} / \mathrm{L}$.

Several articles have reported the involvement of cytokines in the histopathology of cerebral malaria $[44,45]$. Among these cytokines, TNF is thought to play a major role in pathogenesis of cerebral malaria. Others have reported the presence of cytokines in the brain after fatal cases of malaria $[45,46]$. Three SNPs of TNF promoter $-857,-863$ and -1031 were analyzed and the frequency of the designated allele $-857 \mathrm{C} /-863 \mathrm{C} /-1031 \mathrm{C}$ was found to be significantly higher in patients with cerebral malaria than that with UM in area along ThaiMyanmar border [28]. In the present study, the frequency of $-857 \mathrm{C} /-863 \mathrm{C} /-1031 \mathrm{C}$ was found to be $1.3,4.0$ and $3.1 \%$ in Thai, Burmese and Karen patients, respectively. It was noted however for the observed lack of significant difference in frequency of this promoter allele $(-857 \mathrm{C} /-863 \mathrm{C} /-1031 \mathrm{C})$ between the SM and UM groups. The TNF polymorphism was categorized based on the patterns of allele polymorphisms reported by Ubalee [22] and Hananantachai [28]. The first classification-
TNF P-A, TNF P-B, TNF P-C, TNF P-D, TNF P-E and TNF P-F was based on the biallelic polymorphism sites at nucleotides $-238,-308,-857,-863$ and -1031 . The second classification- TNF P1, TNF P-2, TNF P-3, TNF P-4 and TNF P-5 was based on the biallelic polymorphism sites at nucleotides $-857,-863$ and -1031 . No significant association between any pattern of TNF polymorphism as well as each individual single SNPs and disease pathogenicity/severity (SM, UM, VM) including ethnics (Thai, Karen, Burmese) were observed when polymorphisms were classified based on both criteria. The biallelic polymorphic sites at nucleotides -238, $-308,-857,-863$ and -1031 , with seven allele patterns (TNF P-A, TNF P-B, TNF P-C, TNF P-D, TNF P-M1, TNF P-M4 and TNF P-M7) were identified in a previous study in Burmese and Karen patients who lived near Thai-Myanmar border [22] and TNF P-D allele was found to be significantly associated with the high proportion of cerebral malaria (SM) compared with UM cases. Interestingly, the TNF P-M1, TNF P-M4 and TNF P-M7 but TNF P-E and TNF P-F were not found in all the three ethnics under the present investigation. The frequencies of the $-863 \mathrm{C}$ or $-1031 \mathrm{~T}$ allele, the typical polymorphisms of TNF P-D, were found much higher in Swedish (94\% for $-863 \mathrm{C}$ and $80 \%$ for $-1031 \mathrm{~T}$ ) [47] and in Japanese ( $82 \%$ for $-863 \mathrm{C}$ and $84 \%$ for $-1031 \mathrm{~T}$ ) subjects [25] than in the three ethnics under present investigation where the frequencies of $-863 \mathrm{C}$ and $-1031 \mathrm{~T}$ alleles were 38 vs 39\% in Thai, 40 vs 38\% in Burmese and 41 vs $40 \%$ in Karen patients, respectively. The association of single SNP of TNF was also found in other studies in African patients. Two studies were performed in Gambian children and results showed that the TNF -238 A allele was found to be associated with susceptibility to severe malarial anaemia but not to $\mathrm{CM}$ [20]. On the other hand, the neighbouring TNF -308 A allele was associated with CM but not with severe malarial anaemia [48]. Furthermore, data from 1,048 Kenyan children showed the TNF -308 A allele to be significantly associated with high density P. falciparum parasitaemia. Among low birth weight children, the TNF -308 A allele was also found to be associated with 
severe anaemia with a trend toward a risk for severe malaria anaemia [49]. In contrast with other studies, a study conducted in Gabon comparing malaria severity and TNF promoter (TNF P) variants has demonstrated that the frequencies of carriers of distinct TNF variants did not differ significantly in the groups with mild and SM [18]. Moreover, TNF plasma levels were not significantly associated with any of the TNF variants.

\section{Conclusions}

Difference in the expression of HO-1 genotype in different ethnic groups may contribute to different severity of malaria disease. To definitely conclude on the association between malaria pathogenicity/severity and the involvement of genetic polymorphisms of $\mathrm{HO}-1$ (including the inducing effect of cadmum) and TNF, further study with larger sample size estimation based on this preliminary data should be performed with focus on only one ethnic group (Burmese patients, which constitute the majority group of patients in this area).

\section{Acknowledgements}

This work was supported by Thammasat University and The Commission on Higher Education, Ministry of Education, Thailand. We thank staff of Mae Sot General Hospital for their assistance in sample collection.

\section{Author details \\ 'Pharmacology and Toxicology Unit, Graduate Programme in Biomedical Sciences, Thammasat University, Pathumthani, Thailand. ${ }^{2}$ Department of Molecular Immunogenetics, Institute of Tropical Medicine, Nagasaki University, Japan. ${ }^{3}$ Mae Sot General Hospital, Tak Province, Thailand.}

\section{Authors' contributions}

JK performed the molecular genetic studies, participated in the sequence alignment, interpretation of data, performed the statistical analysis and drafted the manuscript. KH participated in the design of the study. MK participated in the molecular genetic studies and sequence alignment. RR participated in sample collection and the study design and coordination. KN participated in the design of the study, performed the statistical analysis and finalised the manuscript. All authors read and approved the final manuscript.

\section{Competing interests}

The authors declare that they have no competing interests.

Received: 31 May 2010 Accepted: 17 September 2010

Published: 17 September 2010

\section{References}

1. Karbwang J, Na-Bangchang K: Clinical application of mefloquine pharmacokinetics in the treatment of $P$. falciparum malaria. Fund Clin Pharm 1994, 8:491-502.

2. Na-Bangchang $\mathrm{K}$, Congpuong $\mathrm{K}$ : Current malaria status and distribution of drug resistance in East and Southeast Asia with special focus to Thailand. The Tohoku Journal of Experimental Medicine 2007, 211:99-113.

3. Dietrich JB: The adhesion molecule ICAM-1 and its regulation in relation with the blood-brain barrier. J Neuroimmunol 2002, 128:58-68.

4. Apinan R, Satarug S, Ruengweerayut R, Tassaneeyakul W, Na-Bangchang K: Cadmium exposure in Thai populations from central, northern and northeastern Thailand and the effects of food consumption on cadmium levels. Southeast Asian J Trop Med Public Health 2009, 40:177-186.

5. Teeyakasem W, Nishijo M, Honda R, Satarug S, Swaddiwudhipong W, Ruangyuttikarn W: Monitoring of cadmium toxicity in a Thai population with high-level environmental exposure. Toxicol Lett 2007, 169:185-195.
6. Simmons RW, Pongsakul P, Saiyasitpanich D, Klinpholap S: Elevated levels of cadmium and zinc in the paddy soils and elevated levels of cadmium in rice grain downstream of zinc mineralized area in Thailand: implications for public health. Environ Geoch HIth 2005, 27:501-511.

7. Järup L, Berglund $M$, Elinder $C G$, Nordberg $G$, Vahter M: Health effects of cadmium exposure - a review of the literature and a risk estimate. Scandinavian Journal of Work, Environment \& Health 1998, 24:1-51.

8. Bernard A, Roels H, Buchet JP, Cardenas A, Lauwerys R: Cadmium and health: the Belgian experience. International Agency for Research on Cancer Science Publications 1992, 118:15-33.

9. Shibahara S, Kitamuro T, Takahashi K: Heme degradation and human disease: diversity is the soul of life. Antioxid Redox Signal 2002, 4:593-602.

10. Shibahara $\mathrm{S}$ : The heme oxygenase dilemma in cellular homeostasis: new insights for the feedback regulation of heme catabolism. The Tohoku Journal of Experimental Medicine 2003, 200:167-86.

11. Tenhunen R, Marver HS, Schmid R: The enzymatic conversion of heme to bilirubin by microsomal heme oxygenase. Proc Natl Acad Sci USA 1968, 61:748-55.

12. Tenhunen R, Marver HS, Schmid R: Microsomal heme oxygenase. Characterization of the enzyme. J Biol Chem 1969, 244:6388-94.

13. Maines MD: Heme oxygenase: function, multiplicity, regulatory mechanisms, and clinical applications. Journal of the Federation of American Societies for Experimental Biology 1988, 2:2557-68.

14. Takeda K, Ishizawa S, Sato M, Yoshida T, Shibahara S: Identification of a cisacting element that is responsible for cadmium-mediated induction of the human heme oxygenase gene. J Biol Chem 1994, 269:22858-22867.

15. Yamada N, Yamaya M, Okinaga S, Nakayama K, Sekizawa K, Shibahara S, Sasaki H: Microsatellite polymorphism in the heme oxygenase-1 gene promoter is associated with susceptibility to emphysema. Am J Hum Gen 2000, 66:187-195.

16. Exner $M$, Schillinger M, Minar E, Mlekusch W, Schlerka G, Haumer M, Mannhalter C, Wagner O: Heme oxygenase-1 gene promoter microsatellite polymorphism is associated with restenosis after percutaneous transluminal angioplasty. J Endovasc Ther 2001, 5:433-440.

17. Wilson AG, Symons JA, McDowell TL, McDevitt HO, Duff GW: Effects of a polymorphism in the human tumor necrosis factor alpha promoter on transcriptional activation. Proc Natl Acad Sci USA 1997, 94:3195-3199.

18. May J, Lell B, Luty AJ, Meyer CG, Kremsner PG: Plasma interleukin-10: Tumor necrosis factor (TNF)-alpha ratio is associated with TNF promoter variants and predicts malarial complications. I Infect Dis 2000, 182:1570-1573.

19. Grau GE, Piguet PF, Vassalli P, Lambert PH: Tumor-necrosis factor and other cytokines in cerebral malaria: experimental and clinical data. Immunol Rev 1989, 112:49-70.

20. McGuire W, Knight JC, Hill AV, Allsopp CE, Greenwood BM, Kwiatkowski D: Severe malarial anemia and cerebral malaria are associated with different tumor necrosis factor promoter alleles. J Infect Dis 1999, 179:287-290.

21. Knight JC, Udalova I, Hill AV, Greenwood BM, Peshu N, Marsh K, Kwiatkowski D: A polymorphism that affects OCT-1 binding to the TNF promoter region is associated with severe malaria. Nat Genet 1999, 22:145-150.

22. Ubalee $R$, Suzuki F, Kikuchi M, Tasanor $\mathrm{O}$, Wattanagoon $\mathrm{Y}$, Ruangweerayut $\mathrm{R}$, Na-Bangchang K, Karbwang J, Kimura A, Itoh K, Kanda T, Hirayama K: Strong association of a tumor necrosis factor-alpha promoter allele with cerebral malaria in Myanmar. Tissue Antigens 2001, 58:407-410.

23. Ausubel FM, Brent R, Kingston RE, Moore DD, Seidman JG, Smith JA, Struhl K: Short Protocols in Molecular Biology John Wiley and Sons. New York 1995.

24. Takeda M, Kikuchi M, Ubalee R, Na-Bangchang K, Ruangweerayut R, Shibahara S, Imai S, Hirayama K: Microsatellite polymorphism in the heme oxygenase-1 gene promoter is associated with susceptibility to cerebral malaria in Myanmar. Japanese Journal of Infectious Diseases 2005, 58:268-71

25. Higuchi T, Seki N, Kamizono S, Yamada A, Kimura A, Kato H, Itoh K. Polymorphism of the $5^{\prime}$-flanking region of the human tumor necrosis factor (TNF)-alpha gene in Japanese. Tissue Antigens 1998, 51:605-12.

26. Wang S: Determination of cadmium in tea by GFAAS. Guang Pu Xue Yu Guang Pu Fen Xi 1998, 18:227-229. 
27. World Health Organisation (WHO): Environmental Health Criteria 134 Cadmium International Programme on Chemical Safety (IPCS) Monograph 1992.

28. Hananantachai H, Patarapotikul J, Ohashi J, Naka I, Krudsood S, Looareesuwan S, Tokunaga K: Significant association between TNF-alpha (TNF) promoter allele $(-1031 \mathrm{C},-863 \mathrm{C}$, and $-857 \mathrm{C})$ and cerebral malaria in Thailand. Tissue Antigens 2007, 69:277-280.

29. Schluesener HJ, Kremsner PG, Meyermann R: Heme oxygenase-1 in lesions of human cerebral malaria. Acta Neuropathol (Berl) 2001, 101:65-68.

30. Clark IA, Awburn MM, Harper CG, Liomba NG, Molyneux ME: Induction of $\mathrm{HO}-1$ in tissue macrophages and monocytes in fatal falciparum malaria and sepsis. Malar J 2003, 2:41.

31. Chen YH, Lin SJ, Lin MW, Tsai HL, Kuo SS, Chen JW, Charng MJ, Wu TC, Chen LC, Ding YA, Pan WH, Jou YS, Chau LY: Microsatellite polymorphism in promoter of heme oxygenase- 1 gene is associated with susceptibility to coronary artery disease in type 2 diabetic patients. Hum Genet 2002, 111:1-8.

32. Kuesap J, Li B, Satarug S, Takeda K, Numata I, Na-Bangchang K, Shibahara S: Prostaglandin $D_{2}$ induces heme oxygenase- 1 in human retinal pigment epithelial cells. Biochem Biophys Res Commun 2008, 367:413-419.

33. Kuesap J, Na-Bangchang K: Possible role of heme oxygenase-1 and prostaglandins in the pathogenesis of cerebral malaria: heme oxygenase- 1 induction by prostaglandin $\mathrm{D}(2)$ and metabolite by a human astrocyte cell line. Korean J Parasitol 2010, 48:15-21.

34. Urade $Y$, Hayaishi $O$ : Biochemical, structural, genetic, physiological, and pathophysiological features of lipocalin-type prostaglandin D synthase. Biochim Biophys Acta 2000, 1482:259-271.

35. Takeda K, Fujita $H$, Shibahara S: Differential control of the metal-mediated activation of the human heme oxygenase- 1 and metallothionein IIA genes. Biochem Biophys Res Commun 1995, 207:160-167.

36. Wittman R, Hu H: Cadmium exposure and nephropathy in a 28-year-old female metals worker. Environ Health Perspect 2002, 110:1261.

37. Peterson DP, Huff EA, Bhattacharyya MH: Determination of cadmium in blood, plasma, and urine by electrothermal atomic absorption spectrophotometry after isolation by anion-exchange chromatography. Anal Biochem 1991, 192:434-440.

38. Martinsen I, Thomassen Y: The Application of Atomic Spectroscopy in the Control of Industrial Exposure to Toxic Elements. In Proceedings of the Second International Conference on Clinical Toxicology and Clinical Chemistry of Metals. Edited by: Brown SS, Savory J. Montreal: Canada; 1983:

39. Zhang ZW, Shimbo S, Watanabe T, Srianujata S, Banjong O, Chitchumroonchokchai C, Nakatsuka H, Matsuda-Inoguchi N, Higashikawa K, Ikeda M: Non-occupational lead and cadmium exposure of adult women in Bangkok, Thailand. Sci Total Environ 1999, 226:65-74.

40. Peterson DP, Huff EA, Bhattacharyya MH: Determination of cadmium in blood, plasma, and urine by electrothermal atomic absorption spectrophotometry after isolation by anion-exchange chromatography. Anal Biochem 1991, 192:434-440.

41. Rosenberg E, Litus I, Schwarzfuchs N, Sinay R, Schlesinger P, Golenser J, Baumeister S, Lingelbach K, Pollack Y: pfmdr2 confers heavy metal resistance to Plasmodium falciparum. J Biol Chem 2006, 281:27039-27045.

42. Sirivarasai J, Kaojaren S, Wananukul W, Srisomerang P: Non-occupational determinants of cadmium and lead in blood and urine among a general population in Thailand. Southeast Asian J Trop Med Public Health 2002, 33:180-187.

43. Wibowo AA, Herber RF, van Deyck W, Zielhuis RL: Biological assessment of exposure in factories with second degree usage of cadmium compounds. Int Arch Occup Environ Health 1982, 49:265-273.

44. Gimenez F, Barraud LS, Fernandez C, Pino P, Mazier D: Tumor necrosis factor $\alpha$ in the pathogenesis of cerebral malaria. Cell Mol Life Sci 2003, 60:1623-1635.

45. Udomsangpetch $R$, Chivapat S, Viriyavejakul P, Riganti M, Wilairatana P, Pongponratin $E$, Looareesuwan S: Involvement of cytokines in the histopathology of cerebral malaria. Am J Trop Med Hyg 1997, 57:501-506.

46. Brown H, Hien TT, Day N, Mai NT, Chuong LV, Chau TT, Loc PP, Phu NH, Bethell D, Farrar J, Gatter K, White N, Turner G: Evidence of blood-brain barrier dysfunction in human cerebral malaria. Neuropathol Appl Neurobiol 1999, 25:331-340.

47. Skoog T, van't Hooft FM, Kallin B, Jovinge S, Boquist S, Nilsson J, Eriksson P, Hamsten A: A common functional polymorphism (C $>A)$ substitution at position -863 in the promoter region of the tumor necrosis factor- $\alpha$
(TNF- $\alpha$ ) gene associated with reduced circulating levels of TNF- $\alpha$. Hum Mol Genet 1999, 8:1443-1449.

48. McGuire W, Hill AV, Allsopp CE, Greenwood BM, Kwiatkowski D: Variation in the TNF - alpha promoter region associated with susceptibility to cerebral malaria. Nature 1994, 371:508-510.

49. Aidoo M, McElroy PD, Kolczak MS, Terlouw DJ, ter Kuile FO, Nahlen B, Lal AA, Udhayakumar $\mathrm{V}$ : Tumor necrosis factor-alpha promoter variant 2 (TNF 2) is associated with pre-term delivery, infant mortality, and malaria morbidity in western Kenya: Asembo Bay Cohort Project IX. Genet Epidemiol 2001, 21:201-211.

doi:10.1186/1475-2875-9-260

Cite this article as: Kuesap et al: Study on association between genetic polymorphisms of haem oxygenase-1, tumour necrosis factor, cadmium exposure and malaria pathogenicity and severity. Malaria Journal 2010 9:260.

\section{Submit your next manuscript to BioMed Central and take full advantage of:}

- Convenient online submission

- Thorough peer review

- No space constraints or color figure charges

- Immediate publication on acceptance

- Inclusion in PubMed, CAS, Scopus and Google Scholar

- Research which is freely available for redistribution

Submit your manuscript at www.biomedcentral.com/submit
Ciomed Central 